\title{
Microwave intermittent drying enhances drying kinetics of banana slices
}

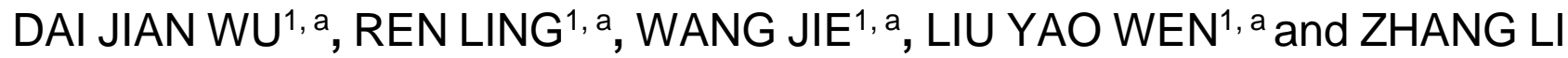 \\ $\mathrm{HUA}^{1, a}$
}

${ }^{1}$ College of Mechanical and Electrical Engineering, Sichuan Agricultural University, 625014, Ya'An, Sichuan Province, China

${ }^{2}$ College of Food Science, Sichuan Agricultural University, 625014, Ya'An, Sichuan Province, China

adaijianwu@126.com, b364720874@qq.com

Keywords: banana slices, microwave intermittent drying, drying kinetic, fitting model

Abstract. Microwave intermittent drying kinetics of banana slices were investigated under different power levels $(250,400,550$ and $700 \mathrm{~W})$, sample thickness $(3,6,9$ and $12 \mathrm{~mm})$, heating time $(11,14$, 17 and 20s) and intermittent time (50, 60, 70 and 80s) during each cycle. Results indicated that all the four factors had significant influence on the drying kinetics, whereas microwave power gave the most significant effect, followed by heating/intermittent time and sample thickness. Drying rate curves illustrated that the drying process of banana slices contained the increasing rate period. Moisture effective diffusivity was advanced with the growth of power level, thickness and heating time. The whole drying time was added with the increase of the intermittent time. When the drying parameters of banana slices changed under the conditions, the moisture effective diffusion coefficient varied from $2.10 \times 10^{-10}$ to $7.83 \times 10^{-9} \mathrm{~m}^{2} \cdot \mathrm{s}^{-1}$.

\section{Introduction}

Banana is one of famous fruits in southern China, which tastes sweet and delicious. It is also multi-function health product, including promoting gastrointestinal peristalsis, soothing nerves, etc. Nowadays, banana is widely planted in China, and the total export production had got 12, 899 thousand tons in $2014^{[1,2]}$.

Due to both seasonal and perishable nature characteristics, it is difficult to keep the fruit long-term preservation with its strong respiratory intensity. According to the research ${ }^{[3,4]}$, the loss rate of banana reaches up to $20 \%-30 \%$. As a result, choosing the efficient storage way for the banana products has become the most important part of the whole processing industrial chain. Drying is one of the most common methods used for banana processing and extending their shelf lives by reducing the moisture content to a low level, which prevents the growth and reproduction of microorganisms and minimize many of the moisture-mediated deteriorative reactions.

Microwave intermittent drying technology is based on the common microwave drying technology while controlling heating time and interval time accurately. Differ to other ways of drying, microwave intermittent drying technology depending on its special heating quality, rapid drying rate and less heating time has become more and more popular. Nowadays, much research has been carried out to investigate the characteristics of microwave intermittent drying technology, especially about litchi, longan, potato, carrot and ginger etc. However, the research about banana slices drying kinetics under the above way dates few ${ }^{[5-7]}$. In this paper, the objectives of current work were to focus on microwave intermittent drying kinetics of banana slices.

\section{Materials and methods}

\section{Raw material}

Fresh bananas were purchased from a local market in Ya'an, Sichuan province of PR China. Bananas of uniform size were selected and stored at $4{ }^{\circ} \mathrm{C}$ before experiments. The average radius of the samples was about $26 \mathrm{~mm}$. The initial moisture content of bananas was $4.68 \mathrm{~kg} \cdot \mathrm{kg}^{-1}$ in dry basis, as determined by the AOAC method no. 934.06. 


\section{Experimental set-up and procedure}
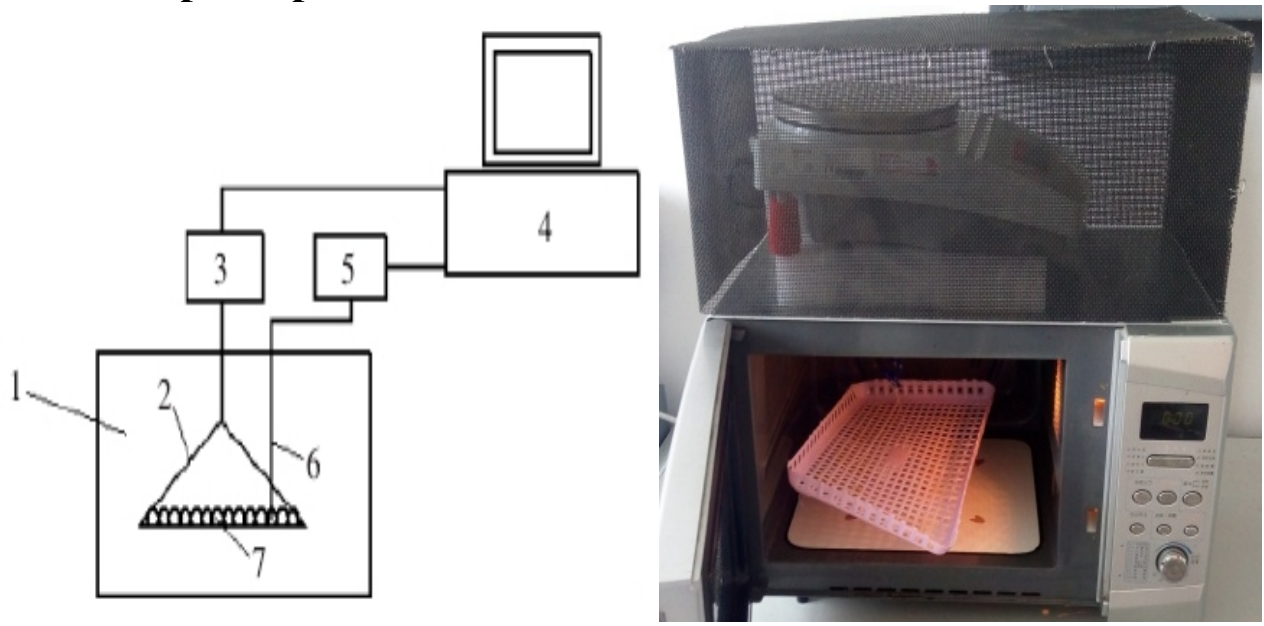

Fig. 1 The structure of microwave intermittent drying equipment

A schematic diagram of equipment used for microwave intermittent drying is shown in Fig. 1. This apparatus basically consist of microwave generator inside the drying chamber to heat the sample, an electronic weighing equipment linked with charging tray to realize automatic weighing, and a Proportional-Integral-Derivative (PID) controller (Omron, model E5CN, Tokyo, Japan) to control drying transmitting power. After the dryer had reached steady conditions for the set points, the banana slices were spread into a single layer onto a silicone rubber tray. As shown in Table 1, the drying experiments were carried out at different transmitting powers $(250,400,550$ and $700 \mathrm{~W})$, heating time (11, 14, 17 and 20s) and intermittent time (50, 60, 70 and 80s) during each cycle on the drying characteristics and quality of banana slices. Drying was continued until the samples reached the desired final moisture content of $0.17 \mathrm{~kg} \cdot \mathrm{kg}^{-1}$ in dry basis. The product was cooled and packed in low density polyethylene bags that were heat sealed. The experiments were performed in triplicate.

\begin{tabular}{ccccc} 
Table 1 Design for experiments with drying parameters inclu \\
\hline $\begin{array}{ccccc}\text { N } \\
\text { o. }\end{array}$ & $\begin{array}{c}\text { Slice thickness } \\
(\mathrm{mm})\end{array}$ & $\begin{array}{c}\text { Microwave } \\
\text { power }(\mathrm{W})\end{array}$ & $\begin{array}{c}\text { Heating } \\
\text { time }(\mathrm{s})\end{array}$ & $\begin{array}{c}\text { Intermittent } \\
\text { time }(\mathrm{s})\end{array}$ \\
\hline 1 & 6 & 250 & 14 & 80 \\
2 & 6 & 400 & 14 & 80 \\
3 & 6 & 550 & 14 & 80 \\
4 & 6 & 700 & 14 & 80 \\
5 & 3 & 400 & 11 & 80 \\
6 & 6 & 400 & 11 & 80 \\
7 & 9 & 400 & 11 & 80 \\
8 & 12 & 400 & 11 & 80 \\
9 & 12 & 250 & 11 & 80 \\
10 & 12 & 250 & 14 & 80 \\
11 & 12 & 250 & 17 & 80 \\
12 & 12 & 250 & 20 & 80 \\
13 & 3 & 250 & 11 & 50 \\
14 & 3 & 250 & 11 & 60 \\
15 & 3 & 250 & 11 & 70 \\
16 & 3 & 250 & 11 & 80 \\
\hline
\end{tabular}

\section{Calculation of moisture effective diffusivity}

The moisture ratio (MR) of banana slices during drying experiments was calculated with a more simplified form as follows ${ }^{[8]}$ :

$$
M R=\frac{M_{t}}{M_{o}} .
$$

Where $\mathrm{M}_{0}$ is the initial moisture content of banana slices, $\mathrm{M}_{\mathrm{t}}$ is the moisture content at time $\mathrm{t}$. 
The drying rate of sample slices during drying experiments was computed using Eq. $(2)^{[9]}$ :

$$
D R=\frac{M_{t_{1}}-M_{t_{2}}}{t_{2}-t_{1}} \text {. }
$$

Where $t_{1}$ and $t_{2}$ is the drying time at different moment respectively during drying with expression in hours; $\mathrm{M}_{\mathrm{t} 1}$ and $\mathrm{M}_{\mathrm{t} 2}$ is the moisture content of samples at $\mathrm{t}_{1}$ and $\mathrm{t}_{2}, \mathrm{~g} \cdot \mathrm{g}^{-1}$.

The calculation of moisture effective diffusivity was determined as shown in Eq. (3) ${ }^{[10-15]}$ :

$$
\ln (M R)=\ln \left(\frac{6}{\pi^{2}}\right)-\left(\pi^{2} \frac{D_{e f f} t}{r_{o}{ }^{2}}\right) \text {. }
$$

There is a linear relationship between the natural logarithm of moisture ratio and drying time of sample slices according to Eq. (3). So the slope can be given from the linear regression of ln (MR) versus time curves, then the effective diffusion coefficient $\left(D_{\text {eff }}\right)$ can be determined.

\section{Results and discussion}

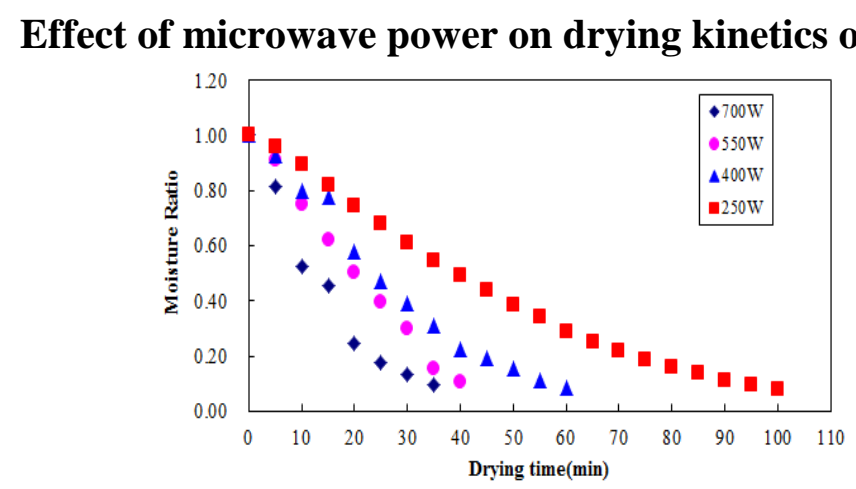

(a)

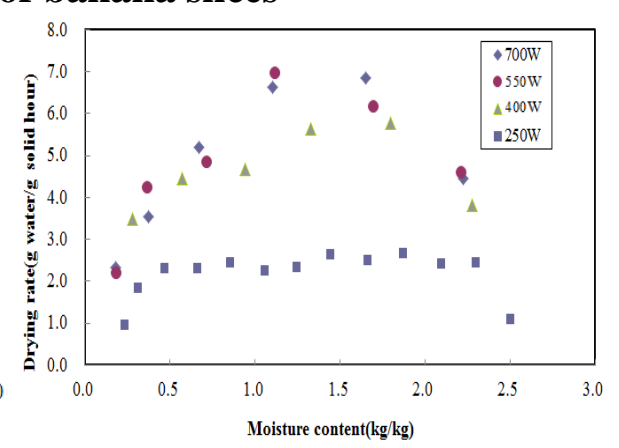

(b)

Fig. 2 Drying kinetics of banana slices at different microwave power level with the heating/intermittent time of $14 \mathrm{~s} / 80 \mathrm{~s}$ and slices thickness of $6 \mathrm{~mm}$

To compare the effect of different microwave power $(250,400,550$ and $700 \mathrm{~W})$ on the drying kinetics of banana slices, the curves of MR versus drying time and curves of drying rate versus moisture content were shown in Fig. 2. It can be seen that the drying time to reach the desired moisture content was approximately 100, 60, 40 and $35 \mathrm{~min}$ with a constant slice thickness of $6 \mathrm{~mm}$ at microwave power of $250,400,550$ and $700 \mathrm{~W}$, respectively. The results confirmed that the drying rate was significantly enhanced with the growth of power level. From Fig. 2b, there contained three stages during the drying of banana slices: accelerated drying stage, constant drying stage and decelerated drying stage. And the constant drying stage gradually drawdown as the increase of microwave power. It is clear that diffusion is the dominant physical mechanism governing moisture movement from interior to surface of banana slices during drying process. Similar results have been reported in literature by other researchers, such as Monukka seedless and American ginseng slices. 


\section{Effect of slice thickness on drying kinetics of banana samples}

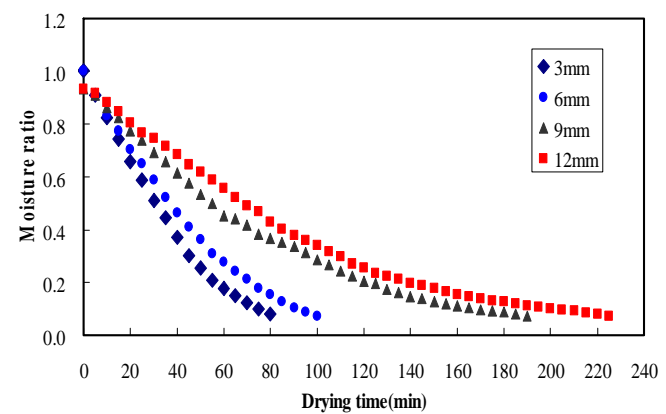

(a)

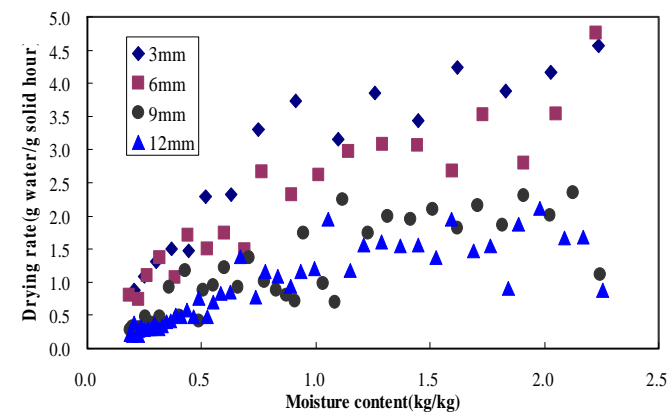

(b)

Fig. 3 Drying kinetics of banana slices at different slices thickness with the heating/intermittent time of $11 \mathrm{~s} / 80 \mathrm{~s}$ and the microwave power of $400 \mathrm{~W}$

Under the drying condition with the microwave power of $400 \mathrm{~W}$ and the heating/intermittent time of $11 \mathrm{~s} / 80 \mathrm{~s}$, the drying curves of banana slices with different thickness levels were investigated. Fig. 3a showed that the greater the thickness, the longer the heating time. Generally compared to the variation trend of the curves, it was found that the heating time did not prolong in proportion as the thickness of banana slices increased. The moisture content of $9 \mathrm{~mm}$ banana slice fell slowdown significantly. This might be because the thickness level was at a relatively high value and the microwave can not reach into the center of the banana slices, which lead to the extension of whole drying time.

As shown in Fig. 3b, it presented drastic fluctuations during the subsequent drying process from 3 to $12 \mathrm{~mm}$. Before the inflection point, the power level had a great impact on banana slices. The stronger the power level, the more moisture diffusion would occur. After the point, the drying rate of banana slices with different thickness fluctuated along with the drying process.

\section{Effect of heating time on drying kinetics of banana slices}

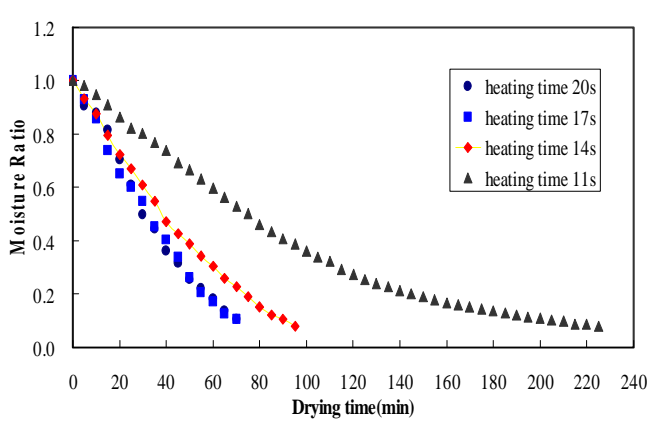

(a)

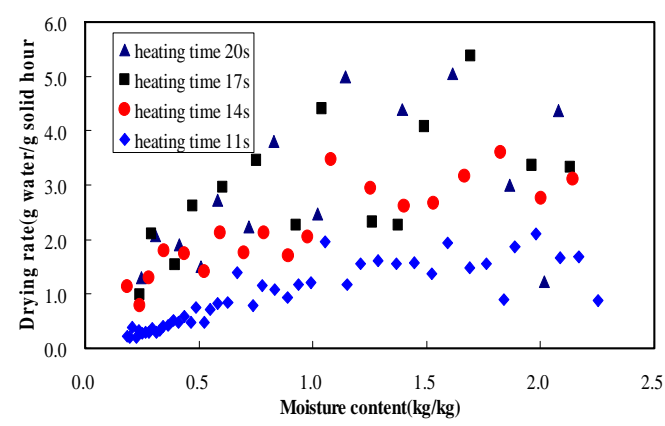

(b)

Fig. 4 Drying kinetics of banana slices at different heating time with the intermittent time of 80 s and the microwave power of $250 \mathrm{~W}$ at $12 \mathrm{~mm}$

The effects of heating time during each cycle on the drying kinetics of banana slices were shown in Fig. 4. Based on the preliminary experiment results, the heating time was selected at 11, 14, 17 and 20 s, respectively. And this was corresponding to the time of sample increased to $50,55,60$ and $65^{\circ} \mathrm{C}$. From Fig. 4b, the curve demonstrated that the whole drying process with heating time of $11 \mathrm{~s}$ got the longest time, while heating time of 20 s during each cycle took the least. Meanwhile, the whole drying time with the heating time of $17 \mathrm{~s}$ and $20 \mathrm{~s}$ were almost the same. When the temperature inside the samples increased to a certain value, parts of the microwave power would transfer from the internal structure, resulting in the energy loss. 


\section{Effect of intermittent time on drying kinetics of banana samples}

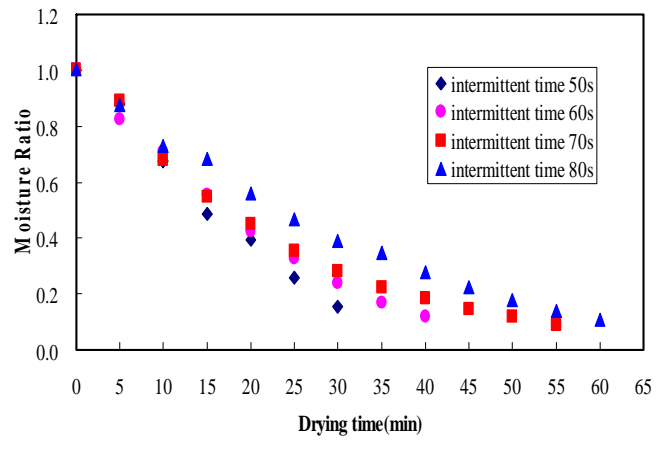

(a)

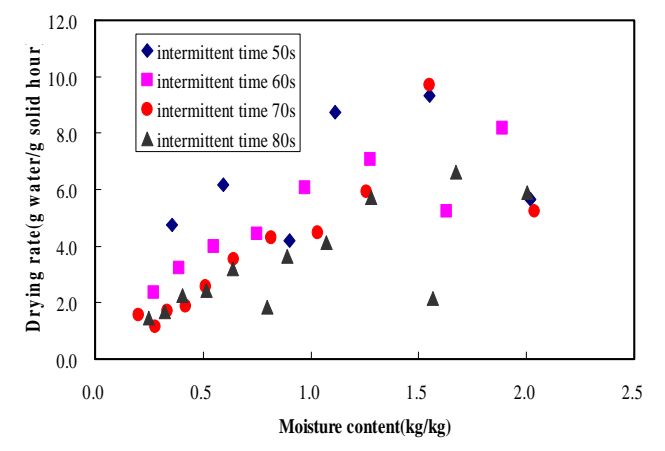

(b)

Fig. 5 Drying kinetics of banana slices at different intermittent time with the intermittent time of $11 \mathrm{~s}$ and the microwave power of $250 \mathrm{~W}$ at $3 \mathrm{~mm}$

During the banana slices with $3 \mathrm{~mm}$ at the intermittent time of $11 \mathrm{~s}$ and the microwave power of $250 \mathrm{~W}$ in the whole drying process, the effects of different intermittent time level on the drying kinetics were investigated. The results showed that the whole drying time increased along with the intermittent time level. It might be due to the reason that the heat energy dissipated during the intermittent time. From Fig. 5b, it can also be seen that the drying curve with intermittent time of 50s showed almost linear variation trend, while the curve at higher level presented a trend of fluctuating downward and contained twists and turning points. It might be because the interval period was coherent and the internal temperature can be maintained within a certain period of time, so that the moisture diffusion rate was relatively stable.

Analysis of moisture effective diffusivity under different conditions

$\underline{\text { Table } 2 \text { Moisture effective diffusion coefficients under different drying condition }}$

\begin{tabular}{|c|c|c|c|c|c|}
\hline No. & condit & & Linear regression fitting formula & $\mathrm{R}^{2}$ & $\begin{array}{c}D_{\text {eff }} \\
\left(10^{-10} \mathrm{~m}^{2} \cdot \mathrm{s}^{-1}\right)\end{array}$ \\
\hline 1 & \multirow{4}{*}{$\begin{array}{l}\text { Microwave } \\
\text { power } \\
\text { (W) }\end{array}$} & 250 & $\operatorname{lnMR}=-0.0257 x+0.2179$ & 0.983 & 15.62 \\
\hline 2 & & 400 & $\operatorname{lnMR}=-0.0422 x+0.2208$ & 0.9821 & 25.65 \\
\hline 3 & & 550 & $\operatorname{lnMR}=-0.055 x+0.2377$ & 0.9388 & 33.43 \\
\hline 4 & & 700 & $\operatorname{lnMR}=-0.0698 x+0.0823$ & 0.9895 & 42.43 \\
\hline 5 & \multirow{4}{*}{$\begin{array}{l}\text { Slice } \\
\text { thickness } \\
(\mathrm{mm})\end{array}$} & 3 & $\ln M R=-0.0138 t+0.01762$ & 0.9878 & 2.10 \\
\hline 6 & & 6 & $\operatorname{lnMR}=-0.0257 t+0.1678$ & 0.9847 & 15.62 \\
\hline 7 & & 9 & $\operatorname{lnMR}=-0.0127 t+0.086$ & 0.9976 & 17.37 \\
\hline 8 & & 12 & $\operatorname{lnMR}=-0.0109 t+0.0925$ & 0.9974 & 26.50 \\
\hline 9 & \multirow{4}{*}{$\begin{array}{l}\text { Heating time } \\
\text { (s) }\end{array}$} & 11 & $\operatorname{lnMR}=-0.0117 t+0.1276$ & 0.9974 & 28.46 \\
\hline 10 & & 14 & $\operatorname{lnMR}=-0.0257 \mathrm{t}+0.204$ & 0.9726 & 62.51 \\
\hline 11 & & 17 & $\operatorname{lnMR}=-0.0322 t+0.2035$ & 0.9686 & 78.32 \\
\hline 12 & & 20 & $\operatorname{lnMR}=-0.032 \mathrm{t}+0.2041$ & 0.9776 & 77.81 \\
\hline 13 & \multirow{4}{*}{$\begin{array}{l}\text { Intermittent } \\
\text { time } \\
(\mathrm{s})\end{array}$} & 50 & $\operatorname{lnMR}=-0.0543 t+0.0932$ & 0.9809 & 8.25 \\
\hline 14 & & 60 & $\operatorname{lnMR}=-0.0533 t+0.1299$ & 0.9853 & 8.10 \\
\hline 15 & & 70 & $\operatorname{lnMR}=-0.0443 t+0.0631$ & 0.9981 & 6.73 \\
\hline 16 & & 80 & $\operatorname{lnMR}=-0.0365 t+0.1053$ & 0.9885 & 5.55 \\
\hline
\end{tabular}

As shown in Table 2, the moisture effective diffusion coefficient $\left(\mathrm{D}_{\text {eff }}\right)$ of the samples increased from $15.62 \times 10^{-10}$ to $42.43 \times 10^{-10} \mathrm{~m}^{2} \cdot \mathrm{s}^{-1}$ as the microwave power level increased from 250 to $700 \mathrm{~W}$. It was found that the $D_{\text {eff }}$ values of the samples varied from $2.10 \times 10^{-10}$ to $26.50 \times 10^{-10} \mathrm{~m}^{2} \cdot \mathrm{s}^{-1}$ when banana slices thickness increased from 3 to $12 \mathrm{~mm}$. It indicated that increasing the thickness could increase the moisture effective diffusion coefficient. Meanwhile, it was observed that the moisture effective diffusion coefficient at different heating times was between $28.46 \times 10^{-10}$ and $78.32 \times 10^{-10}$ $\mathrm{m}^{2} \cdot \mathrm{s}^{-1}$. The Deff values at different interval periods varied from $5.55 \times 10^{-10}$ to $8.25 \times 10^{-10} \mathrm{~m}^{2} \cdot \mathrm{s}^{-1}$, which were significantly less than other variation factors. The $\mathrm{D}_{\text {eff }}$ values between 50 s and 60 s were almost 
the same. And the intermittent time at 50 s was 1.48 times compared to the $80 \mathrm{~s}$, indicating that reduce the intermittent time had beneficial effect on improving the drying rate.

\section{Conclusions}

The effect of heating time, intermittent time, slice thickness and power level on the kinetics of banana slices were examined in this investigation. All of the above parameters had significant impact on the drying rate. And the moisture effective diffusion coefficient was related to power level, heating/intermittent time, except the slice thickness.

During the whole drying process of banana slices under different microwave power level, it contained accelerated drying stage, constant drying stage and decelerated drying stage. An inflection point existed during the slice thickness varied from $9 \mathrm{~mm}$ to $12 \mathrm{~mm}$. The whole drying time was added with the increase of the intermittent time. When the drying parameters of banana slices changed under the conditions, the moisture effective diffusion coefficient varied from $2.10 \times 10^{-10}$ to $7.83 \times 10^{-9} \mathrm{~m}^{2} \cdot \mathrm{s}^{-1}$.

\section{Acknowledgements}

This work was financially supported by the Science Technology Project of Sichuan (Grant No. 17ZB0331) and Natural Science Foundation of Sichuan (Grant No. 035Z1986).

\section{References}

[1] Huang M. X., Lin Y. X., Lin H. T., Li H., Lin Y. F., Lin Z. Q. Optimization of microwave-vacuum drying conditions of banana slices. Transactions of the Chinese Society of Agricultural Engineering, 334(3): 204-209. (2014)

[2] Duan Z. H. Modern sterilization technology of application in food industry. Food and Nutrition in China, 21(9): 28-31. (2010)

[3] Zhang Q. Q., Wen H. X., Xu M. D., Yuan Y. J., Shi F. Development of vacuum drying technology of kiwifruit slices. Chinese Journal of Vacuum Science and Technology, 33(1):1-4. (2013)

[4] Wen H. X., Zhang Q. Q. Research on vacuum drying control system and process for kiwifuits. Chinese Journal of Vacuum Science and Technology, 32(12): 1149-1153. (2012)

[5] Sun D. W. Emerging technologies for food processing. London: Elsevier Academic Press, 507-511. (2011)

[6] Li H., Lin H. T., Yuan F., Lin Y. F., Chen Y. H. Microwave-vacuum drying characteristics and kinetics model of litchi pulp. Transactions of the Chinese Society of Agricultural Machinery, 43(6): 107-112. (2012)

[7] Han Q. H., Li S. J., Ma J. W., Zhao D. L., Yang B. N. Analysis on energy consumption and product quality of microwave vacuum drying and puffing apple slices. Transactions of the Chinese Society of Agricultural Machinery, 39(1): 74-77. (2008)

[8] Zhu D. Q., Wang J. X., Qian L. C. Optimization of technical parameters of microwave-vacuum drying of Chinese gooseberry slices. Transactions of the CSAE, 25(3): 248-252. (2009)

[9] Huang Y., Huang J. L., Zheng B. D. Microwave vacuum drying properties and kinetics model of white fungus. Transactions of the CSAE, 26(4): 362-367. (2010)

[10]Li B., Lu F., Liu B. G. Microwave-vacuum drying characteristics and process optimization of agaricus bisporus slices. Transactions of the CSAE, 26(6): 380-384. (2010) 
[11] Giri S. K., Prasad S. Drying kinetics and rehydration characteristics of microwave-vacuum and convective hot-air dried mushrooms. Journal of Food Engineering, 78(2): 512-521. (2012)

[12] Figiel A. Drying kinetics and quality of vacuum-microwave dehydrated garlic cloves and slices. Journal of Food Engineering, 94(1): 98-104. (2009)

[13] Bondaruk J., Markowski M., Blaszczak W. Effect of drying conditions on the quality of vacuum-microwave dried potato cubes. Journal of Food Engineering, 81(2): 220-226. (2014)

[14]Lin T. M., Durance T. D., Scaman C. H. Characterization of vacuum microwave. Air and Freeze Dried Carrot Slices, 53(2): 147-149. (2011)

[15]Che G., Li C. H., Wang C. Experimental study on pteridium aquilinum vacuum drying. Transactions of the Chinese Society of Agricultural Engineering, 22(5): 165-168. (2006) 